\title{
Validating the Role of African Indigenous Vegetables for Food and Nutrition Security in Uganda
}

\author{
Bosco Bua and Christopher Onang \\ Department of Agriculture, Kyambogo University, P.O. Box 1, Kyambogo, Kampala 256-414, Uganda
}

\begin{abstract}
African indigenous vegetables (AIVs) play an important role in house hold food and nutrition security among many communities in Uganda. However, there is limited information on the value chain. Yet, the contribution of AIVs in terms of food and nutrition security is undisputable. A cross sectional survey targeting 60 respondents including farmers, key informants and extension officers was conducted to assess the systems of production system of the AIVs, profile an inventory and diversity of the cultivated AIVs in Agweng sub-county, Lira district. Semi-structured questionnaires and direct field observation were used to gather the necessary data. The findings revealed that AIVs form a very important part of the diets of the local populace both during the normal and off seasons as well as hard times among others. However, a number of constraints were reported to hinder the AIVs value chain including lack of quality seed, competition from exotic vegetables, low market demand, pests and diseases infestation, among others. The most commonly cultivated and consumed vegetables were cowpeas, hibiscus, pumpkins and crotolaria among others. The reasons for cultivation and consumption included source of food, high nutritive value and short maturity period. Other reasons were medicinal, resistance to pests and diseases, source of cash income and resilient to harsh weather conditions. In contrast, lack of quality seeds, bitterness, low market demand and difficulty in preparation contributed to their neglected use. Therefore, in the wake of climate change and variability there is need for deliberate investment to improve adaptability and acceptance of these vegetables. There is also need for sensitization of farmers on the benefits of AIVs, developing an effective means of improved seed production and distribution to replace the farmer-to farmer seed exchange and conservation of AIVs germplasm as the strategies to improve AIVs production in the study area.
\end{abstract}

Key words: Acceptance, consumption, constraints, value chain.

\section{Introduction}

Indigenous vegetables have been the mainstay of human diets for centuries, providing millions of consumers with important micronutrients, proteins, fibres and energy needed to maintain health and promote immunity against infections [1, 2]. According to Muchunguzi et al. [3], indigenous vegetables are used in many ways to improve the diet and health of people in developing countries. Because of the multiple uses and plant parts that can be eaten, indigenous vegetables play an important role in food security [4]. However, insufficient attention has been given to these local resources within the mainstream food security development and management interventions [5]. Also, only a limited range of

Corresponding author: Bosco Bua, Ph.D., associate professor, research fields: crop science and plant pathology. indigenous vegetables are utilised for food and cash in Uganda [6, 7].

Although, African indigenous vegetables (AIVs) form a significant and inexpensive source of a balanced diet for the poor rural households in Africa, vegetable consumption is often regarded as a poor man diet during most times; the nutrients are destroyed during cooking hence reduced effectiveness in ensuring food security as few indigenous vegetables are cultivated. Accordingly, integration of indigenous vegetables into the farming systems would improve their potential utilization [3]. According to Uusiku et al. [8], consumption of AIVs helps in maintaining a balanced diet and averting the chronic effects of malnutrition. However, most of AIVs have been neglected or underutilized [9]. Also, information on cultivation practices of indigenous vegetables is not 
very comprehensive because most indigenous vegetables are generally regarded as weeds and are always labeled as not worth the space they occupy. Accordingly, indigenous vegetables range from wild to cultivated species with varying categories of domestication including wild but harvested in time of food scarcity, wild but regularly harvested or semi-wild, partly protected or harvested from fallow land, cultivated in mixtures (patches) in traditional farming systems, and cultivated in small-scale market gardens [1-3]. Consequently, exploiting the agronomic and yield potential of these vegetables would be of fundamental importance for food and nutrition security as well livelihoods strategies of households threatened by migration, civil disorder, or diseases such as HIV/AIDS. While a few of these species have been domesticated or semi-domesticated, most of them still grow as weeds or wild in disturbed and cultivated areas [10, 11]. However, there is limited information on the role of AIVs for food and nutrition security in Agweng sub sub-county.

\section{Objective}

The objective of this study was to validate the role of AIVs in household food security and security in Agweng sub county, Lira district, Uganda.

\section{Methodology}

A cross sectional survey targeting 60 respondents including farmers, extension workers, opinion and political leaderships was conducted to validate the role of AIVs for food and nutrition security in Agweng sub-county, Lira district in northern Uganda. Agweng Sub County is located at the extreme northern part of Lira district, approximately 26 km along Lira-Kitgum road. Agweng Sub County is divided into seven parishes with a total of 86 villages. However, only three parishes namely Abala, Angolocom and Te-adwong were selected due to the intensity of production and popularity of cultivated indigenous vegetables than in the other parishes. From each parish, 15 farmers were randomly selected from the Local Council one (LC1) registers. In total, sixty respondents (60) were interviewed including farmers (45), extension workers (3), opinion leaders (6) and political leaders (6). Semi-structured questionnaires and direct field observation were used to gather the necessary information. Data were analysed using SPSS computer package.

\section{Results and Discussion}

The age of the respondents is presented in Table 1. Slightly over $60 \%$ were in the age brackets of 31-60 years as opposed to 20-30 years and over 60 years, respectively. The marital status of the respondents is presented in Table 2. Seventy five percent of the respondents were married compared to the singles. The land owned by the respondents is presented in Table 3. The majority of the respondents owned between 2-4 acres of land compared to those with less than 2 acres. However, most of the land were customarily owned in comparison to the leases (Table 4). The most commonly encountered AIVs in Agweng sub county is presented in Table 5. However, they were either grown deliberately or volunteered. Cowpeas, Hibiscus spp., Pumpkins and Crotolaria were reportedly the mostly commonly grown compared to the spider plant and jute mallow. In contrast, spider plant, jute mallow, amaranths and cherry tomatoes were the only African indigenous vegetables which were never planted but grow by themselves whenever conducive environment is prevalent. In fact, these were commonly grown as home gardens, intercropped and sole cropped (Table 6). The reasons advanced for growing and collecting the indigenous vegetables is presented in Fig. 1. The most common reasons for cultivation or collection of AIVs included food, medicine, nutritive value, resilience to adverse weather conditions and resistance to pests and disease among others. However, a number of constraints were also reported to hinder the production of AIVs (Fig. 2). The most serious constraints 
Table 1 Age of respondents in Agweng Sub county, 2016.

\begin{tabular}{ll}
\hline Age bracket (Years) & Frequency (\%) \\
\hline $20-30$ & 16.7 \\
$31-40$ & 23.3 \\
$41-50$ & 23.3 \\
$51-60$ & 20.0 \\
Above 60 & 16.7 \\
Total & 100 \\
\hline
\end{tabular}

Table 2 Marital status of respondents in Agweng sub county, 2016.

\begin{tabular}{ll}
\hline Marital status & Frequency (\%) \\
\hline Married & 75.0 \\
Single & 3.3 \\
Widowed & 21.7 \\
Total & 100 \\
\hline
\end{tabular}

Table 3 Land size (acres) owned by the respondents in Agweng sub-county, 2016.

\begin{tabular}{ll}
\hline Land size (Acres) & Frequency (\%) \\
\hline Less than 2 & 13.3 \\
$2-4$ & 60.0 \\
$5-7$ & 26.7 \\
Total & 100.0 \\
\hline
\end{tabular}

to AIVs production were competition from exotic vegetables, low market demand, lack of seed, adverse weather conditions, shortage of land, pest and diseases, loss of habitat for the wild relatives and lack of knowledge. Nevertheless, AIVs continue to strive in the community due to a variety of information sources on production (Table 7). The most and least common source of information on production of AIVs was fellow farmers and extension workers, respectively.

Table 4 Land ownership by the respondents, Agweng sub county, 2016.

\begin{tabular}{ll}
\hline Land ownership & Frequency \\
\hline Customary & 80 \\
Leased & 5.0 \\
Both & 15.0 \\
Total & 100.0 \\
\hline
\end{tabular}

Table 5 Commonly encountered African indigenous vegetables (AIVs) in Agweng Sub County, 2016.

\begin{tabular}{lll}
\hline \multirow{2}{*}{ Types } & Cultivated & Volunteered plants \\
\cline { 2 - 3 } & Frequency (\%) & Frequency (\%) \\
\hline Cowpeas & 100 & - \\
Crotalaria & 66.7 & - \\
Spider plant & 21.7 & 100 \\
Jute mallow & 11.7 & 100 \\
Hibiscus sabdariffa & 100 & - \\
Pumpkins & 78.3 & 21.7 \\
Amaranths & 11.7 & 58.4 \\
Tomato & & 36.7 \\
\hline
\end{tabular}

Table 6 Production systems of AIVs in Agweng sub county, 2016.

\begin{tabular}{lll}
\hline S/No. & Production system & Frequency (\%) \\
\hline 1 & Home garden & 78.3 \\
2 & Arable fields (intercrop) & 43.3 \\
3 & Arable fields (grown solely) & 31.7 \\
\hline
\end{tabular}

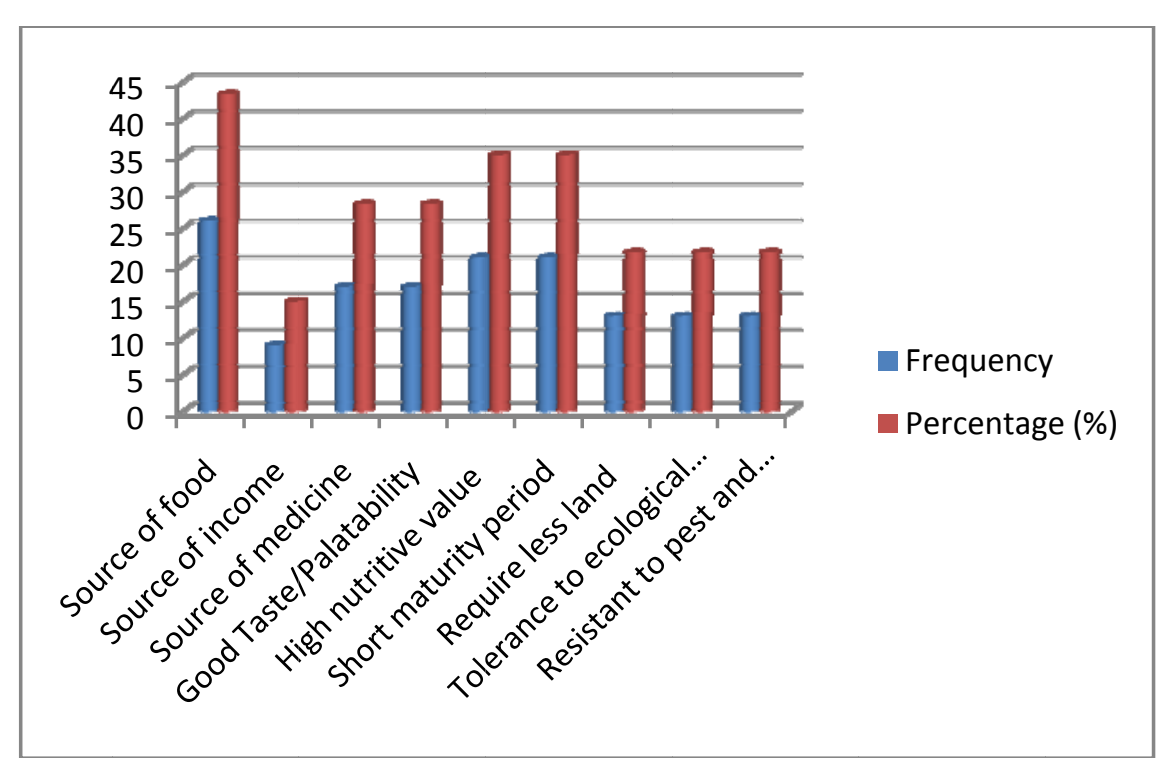

Fig. 1 Reasons for cultivation and collection of the cultivated AIVs in Agweng sub county, 2016. 


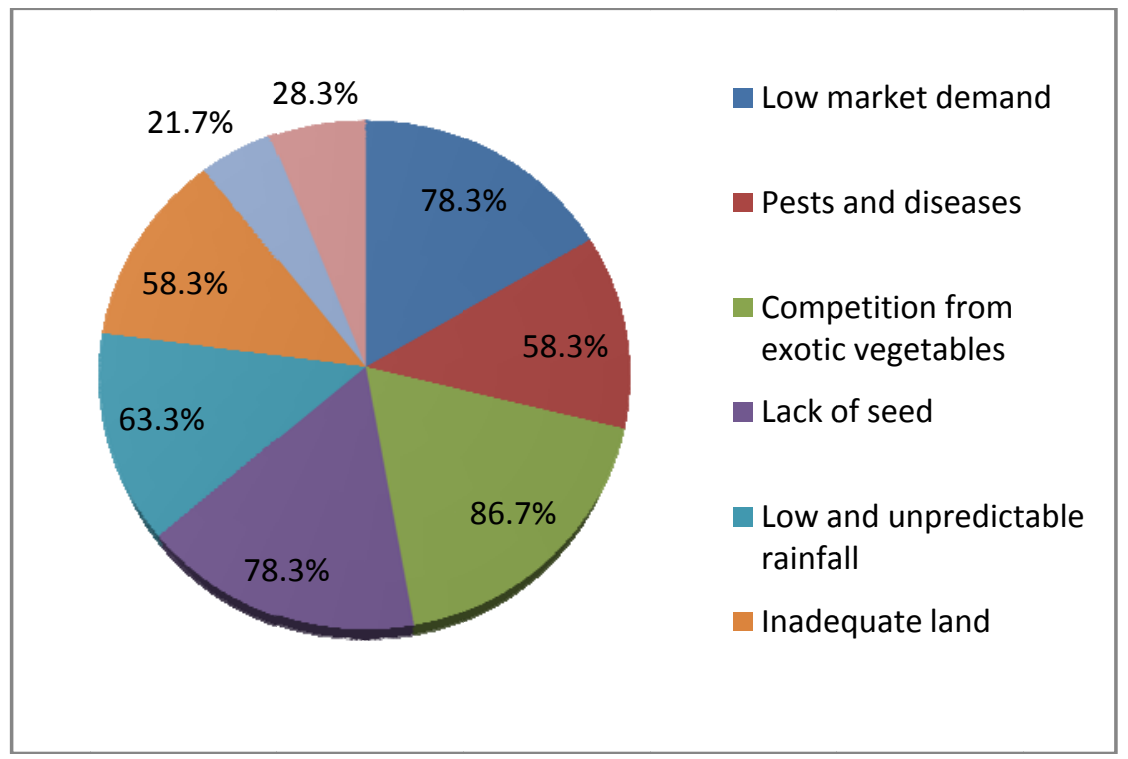

Fig. 2 Constraints to AIV production in Agweng Sub County, 2016.

Table 7 Sources of information on production of AIVs for farmers in Agweng sub county, 2016.

\begin{tabular}{ll}
\hline Source of information & Frequency (\%) \\
\hline Fellow farmers & 100 \\
Friends & 73 \\
Neighbours & 25 \\
Parents & 27 \\
Community elders & 68 \\
Relatives & 27 \\
Extension workers & 05 \\
\hline
\end{tabular}

Table 8 Strategies to conserve and domesticate AIVs in Agweng Sub county, 2016.

\begin{tabular}{ll}
\hline Strategies to domesticate wild AIVs & Frequency (\%) \\
\hline Seed collection & 43.3 \\
Environmental conservation (e.g. & 23.3 \\
forests and swamps) & \\
Awareness creation and sensitization & 66.7 \\
of farmers & 23.3 \\
Establish conservation centres & 21.7 \\
Investment in research & 21.7 \\
\hline Seed multiplication and distribution & \\
\hline
\end{tabular}

However, a number of strategies were highlighted for conserving and preserving the AIVs including awareness creation and sensitisation as well as seed collection among others (Table 8).

\section{Discussion}

Although, different food sources contribute to food and nutrition security, the role of AIVs and traditional crops in the survival strategies of rural people has only recently been recognized $[6,7,9]$. In fact, indigenous vegetables tend to have shorter production cycles and require fewer inputs among others. Vegetables can therefore support rural, peri-urban and urban populations both in terms of subsistence and income generation without requiring large capital outlays. However, there has been a general decline in the consumption of these vegetables over the years, a factor attributed to unavailability and disappearing knowledge particularly among the younger generations [12, 13]. Additionally, the diversity of AIVs is being seriously eroded as a result of multiplicity of environmental, political and socio-economic factors. This probably may explain why only very few AIVs were encountered during this study. These vegetables were reportedly either cultivated or nurtured from the volunteered plants. Among the most notably grown vegetables were cowpea (Vigna unguiculata), Hibiscus (Hibiscus sabdariffa), Crotolaria and pumpkins. Conversely, spider plant, jute mallow and amaranths grew by themselves. According to Ref. [13-15], hundreds of plant species are consumed as vegetables though only about 20 crops are produced in intensive cropping systems. AIVs were considered the most important 
groups of food crops due to a variety of reasons including source of food and income, medicine, nutritive value, tastiness, ability to tolerate harsh environmental conditions, pests and diseases infestations among others [16, 17]. Moreover, available evidence showed that hunger and poverty alleviation does not always depend on new crop varieties that are bred in laboratory but reigniting interest and taste for indigenous and traditional foods can help improve nutrition, income, restore biodiversity and pressure on local food culture and poverty alleviation. Accordingly, it is now well recognized that food security cannot be delinked from nutrition security to which consumption of indigenous vegetables significantly contributed [18]. Consequently, continued investments in AIVs research and development are thus a vital weapon in the continuing battle against poverty and hunger alleviation worldwide. This is because indigenous vegetables offer unique opportunities to diversify farming systems to ensure food security at household levels because they are nutritious and offer cheaper alternatives to the more expensive exotic counter parts with lower nutritional value. According to PROTA [19], Africa has diverse vegetable species of which the primary used vegetables encompasses 53 different botanical families; of which more than $60 \%$ are pan-African. However, the majority of African vegetable species are of localised importance either due to their limited distribution, or their potential as vegetables is known to specific geographic communities or the species is not part of the local food culture. Additionally, the potential of indigenous vegetables to address food and nutrition security challenges is largely unexploited due to lack of investment to improve yields, market, and negative perception as a poor man's food. Knowledge and information are also lacking on the production constraints and the diversity of indigenous vegetables collected and grown by the local communities. Besides, most indigenous vegetables still grow in the wild, lack recommended agronomic practices, have short shelf life, inadequate preservation and storage practices. Moreover, many are still regarded as weeds of low value [2, 3] and susceptible to a number of production constraints [20]. In fact, the promotion and integration of indigenous vegetables into farming systems would assist in their protracted use for food and nutrition security as well eventual conservation. Therefore, with the changing climate and marginal soils common among the resource poor farmers coupled with the increasing food prices, indigenous vegetables would provide some relief. Additionally, indigenous vegetables can produce better yields in poor conditions with fewer inputs and less labour than other staples, making it particularly suitable for households threatened by migration, civil disorder, or diseases such as HIV/AIDS [2, 21]. As a result AIVs, provide a source of cheap but highly nutritive food while contributing to the resilience of the community to changes in climatic conditions as they are well adapted to the ecological conditions of the area. Besides, providing essential nutrients, AIVs are also presumably integral health boosters and sources of traditional medicines [22]. In fact, studies on chemical composition of indigenous vegetables and fruits have shown that they contain invaluable amounts of phytochemicals including crude protein, fat and oil, energy, vitamins and minerals [8, 23]. The majority of the respondents were women compared to men. This is expected because women are the ones who are in charge of preparing and ensuring that the family is well catered for in terms of quantity and quality of meals eaten at home/in house. Also, it is possible women are the ones responsible for the cultivation, collection and preparation of vegetables for food and nutrition security as opposed to men who are only interested in cash crops [15]. In fact, High and Shackleton [24] observed that home gardens are traditional land-use practices near the homestead where crop plants especially vegetables are grown for household consumption. In fact, the majority of the 
respondents were married compared to the singles indicating that AIVs are mainly food for the older people in the community as opposed to the younger generations. Elsewhere, it has been reported that the younger generations dislike vegetables because of the bitter taste, non-attractiveness and palatability [2]. Additionally, this may also be attributed to disappearing knowledge on the production of AIVs. This is because traditionally information sources were passed on from older generations to the younger generations through oral culture. In this study, it was observed that extension services were either non-existent or inefficient. Accordingly, conventional agricultural extension workers normally discouraged farmers from intercropping or nurturing AIVs in their fields because of competition with the planted crop and thereby reduced yields. In fact, lack of adequate knowledge on how to produce, store and distribute quality seeds may be another factor which is normally overlooked by the farmers among themselves [9]. Also, the introduction and adoption of exotic vegetables may be responsible for the disappearance of some of the AIVs [25]. Sensitization of the public would therefore help to reorient the public demand towards such AIVs hence stirring up the need to domesticate such them. Therefore, the protection of the habitat for the wild species and conservation of the forests with rich species and wetlands would be a valuable strategy because this would safeguard the continued existence of AIVs as well as preserve the germplasm which is very vital for future plants breeding. Other strategies would entail establishing conservation centres, conducting more research about those AIVs collected from the wild to discover their potential in cultivated environment and the government should multiply the seeds of those AIVs and distribute to farmers for planting.

\section{Conclusions}

African indigenous vegetables were considered of multiple uses of which food and nutrition security ranked highest. However, a number of constraints were highlighted as affecting the production and utilization of the AIVs. Therefore, the promotion and integration of indigenous vegetables into farming systems would assist in their protracted use for food and nutrition security as well eventual conservation.

\section{References}

[1] Rubaihayo, E. B. 1997. "The Contribution of Indigenous Vegetables to Household Food Security in Uganda." In African Crop Science Conference Proceedings 3: 1337-40.

[2] Vorster, H. J., and Jansen van Rensburg, W. S. 2005. "Traditional Vegetables as a Source of Food in South Africa.” African Crop Science Conference Proceedings 7: 669-72.

[3] Musinguzi, E., Kikafunda, J. K., and Kiremire, B. T. 2006. "Utilization of Indigenous Food Plants in Uganda: A Case Study of South-western Uganda.” African Journal of Food Agriculture Nutrition and Development 6 (2): $1-21$.

[4] Fox, F. W., and Norwood Young, M. E. 1982. Food from the Veld: Edible Wild Plants of Southern Africa, Delta Books, Johannesburg, South Africa.

[5] Adebooye, O. C. and Ajayi, O. A. 2008. "Future of the Nigerian Under-exploited Indigenous Fruits and Vegetables in the Era of Climate Change: The Need for Farmers Education.” In Proceeding of the Conference on International Research on Food Security, Natural Resource Management and Rural Development, University of Hohenheim, October 7-9, 2008.

[6] Rubaihayo, E. B. 1999. "Factors Affecting Production and Utilization of Indigenous Vegetables." In African Crop Science Conference Proceedings 4: 655-9.

[7] Nkwiine, C., and Tumuhairwe, J. K. 2004. "Effect of Market-oriented Agriculture on Selected Agro Biodiversity, Household Income and Food Security Components.” Uganda Journal of Agricultural Sciences 9: 680-7.

[8] Uusiku, N. P., A. Oelofse, A., Duodu, K. G., Bester, M. J., and Faber, M. 2010. "Nutritional Value of Leafy Vegetables of Sub-Saharan Africa and Their Potential Contribution to Human Health: A Review.” Journal of Food Composition and Analysis 23: 499-509.

[9] Abukutsa, M. O. O. 2007. "The Diversity of Cultivated African Leafy Vegetables in Three Communities in Western Kenya.” African Journal of Food, Agriculture, Nutrition and Development 7 (3).

[10] Kemei, J. K., Waataru, R. K., and Sememe, E. N. 1995. "The Role of National Genebank of Kenya in the 
Collecting, Characterization and Conservation of Traditional Vegetables. National Gene Bank of Kenya, Kikuyu, Kenya." In Proceedings of the IPGRI International Workshop on Genetic Resources of Traditional Vegetables in Africa. Conservation and use 29th-31st August, 1995, ICRAF-HQ Nairobi, Kenya.

[11] Maundu, P. G., Ngugi, G., and Kabuye, C. 1999. Traditional Food Plants of Kenya. Kenya Resource Centre, Indigenous Knowledge. National Museums of Kenya.

[12] Shackleton, C. M., Pasquin, M. W., and Drescher, A. W. 2009. African Indigenous Vegetables in Urban Agriculture. London: Earthscan.

[13] Mpala, C., Dlaminia, M., and Sibandaa, P. 2013. "The Accessibility, Utilisation and Role of Indigenous Traditional Vegetables in Household Food Security in Rural Hwange District.” International Open \& Distance Learning Journal 1 (3): 40-8.

[14] Siemonsma, J. S., and Kasem, P. 1994. Prosea: Plant Resources of South-east Asia, 8-Vegetables, 2nd ed., Prosea Foundation, Indonesia.

[15] Keller, G. 2004. “African Nightshade, Eggplant, Spider Flower-Production and Consumption of Traditional Vegetables in Tanzania from the Farmers' Point of View.” MSc. Thesis, Universität, Göttingen, Germany.

[16] Oniang’o, R. K., Shiundu, K., Maunda, P. and Johns, T. 2006. "Diversity, Nutrition and Food Security-The Case of African Leafy Vegetables.” Hunger and Poverty: The Role of Biodiversity, edited by Bala Ravi, S., Hoeschle-Zeledon, I., Swaminathan, M. S., and Frison, E. Rome, Italy: IPGRI, 86-100.

[17] Kamga, R., Kouame, C., and Akyeampong, E. 2013. "Vegetable Consumption Patterns in Yaoundé, Cameroon.” African Journal of Food, Agriculture, Nutrition and Development 55 (4): 613.
[18] Keatinge, J. D. H., Yang, R. Y., Hughes, J. d'A., Easdown, W. J., and Holmer, R. 2011. "The Importance of Vegetables in Ensuring both Food and Nutritional Security in Attainment of the Millennium Development Goals.” Food Security 13: 4.

[19] Plant Resources of Tropical Africa (PROTA). 2005. “Comparative Data on 275 Vegetables.” In Vegetables of Tropical Africa: Conclusions and Recommendations based on PROTA 2: Vegetables, edited by Bosch, C.H., Borus, D. J., and Siemonsma, J. S. PROTA Foundation, Wageningen, The Netherlands.

[20] Diouf, M., Gueye, M., Faye, B., Dieme, O., and Lo, C. 2007. "The Commodity Systems of Four Indigenous Leafy Vegetables in Senegal.” Water SA 33: 343-8.

[21] Flyman, M. V., and Afolayan, A. J. 2006. "A Survey of Plants Used as Wild Vegetables in Four Districts of Botswana." Ecology of Food and Nutrition 45: 405-15.

[22] Tumwet, T. N., Kangethe, E. K., Kogi-Makau, W., and Mwangi, A. M. 2014. "Diversity and Immune Boosting Claims of Some African Indigenous Leafy Vegetables in Western Kenya.” African Journal of Food, Agriculture, Nutrition and Development 14 (1): 1684-5374.

[23] Adebooye, O. C., and Opabote, J. T. 2004. "Status of Conservation of the Indigenous Leaf Vegetables and Fruits of Africa." African Journal of Biotechnology 3: 700-5.

[24] High, C. and Shackleton, C. M. 2000. "The Comparative Value of Wild and Domestic Plants in Home Gardens of a South African Rural Village.” Agroforestry Systems 48 (2): $141-56$

[25] Masayi, N., and Netondo, G. 2012. "Effects of Sugarcane Farming on Diversity of Vegetable Crops in Mumias Division, Western Kenya." International Journal of Biodiversity and Conservation 4 (13): 515-24 